Original Article

\title{
Toxic Effects of Food Azo Dye Tartrazine on the Brain of Young Male Albino Rats: Role of Oxidative Stress
}

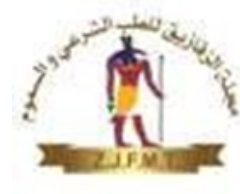

\section{Nema allah Mohamed Hosieny ${ }^{1}$, Mona El-demerdash Ibrahim ${ }^{1}$, Samah M Ahmed $^{2}$ and Mohammad Z. M. Hassan ${ }^{1}$}

Departments of Forensic Medicine and Clinical Toxicology ${ }^{1} \&$ Histology and Cell Biology ${ }^{2}$, Faculty of Medicine, Zagazig University, Egypt.

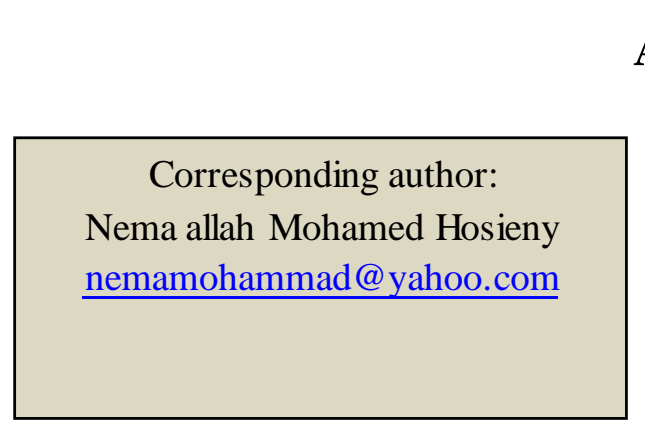

\section{ABSTRACT}

current study was to evaluate the possible toxic effects of tartrazine on the brain of young albino rats. Material and methods: Eighteen young male albino rats were randomly divided into 3 equal groups; Group I (negative control group), Group II (positive control group): each rat received $1 \mathrm{ml}$ distilled water once daily and Group III (tartrazine group): each rat received $320 \mathrm{mg} / \mathrm{kg}$ tartrazine dissolved in $1 \mathrm{ml}$ distilled water once daily by oral gavage. After 4 weeks of daily administration, rats of all groups were sacrificed, and the brains were harvested and prepared for evaluation of oxidative stress markers; glutathione peroxidase (GPx) and malondialdehyde (MDA) as well as histopathological examination by light microscope. Results: The results of the study revealed significant decrease in GPx activity and significant increase in MDA level in tartrazine group as compared to control groups. This was associated with significant histopathological changes in the brain including neuronal apoptosis, cellular infiltration, vacuolations and congested vasculature. Conclusion: Tartrazine toxicity induced severe brain damage in young male albino rats in the form of affection of the general architecture of the brain associated with increased oxidative stress. Recommendations: It is recommended that consumption of foods containing food colorant tartrazine should be restricted especially for children.

Key words: Food additives, Tartrazine, Brain, Young rats, Oxidative stress.

\section{INTRODUCTION}

For centuries, food additives have been used to maintain the quality of food, make food more attractive, improve stability with a resulting reduction in waste, and provide efficient aids in food processing, packaging, storage and transportation (Pavithra and Jaikumar, 2019).

Over the past few decades, the use of food additives has grown Vol. (19) No. (1) January 2021 
enormously. Nearly 75 percent of Western diets today are estimated to cons ist of various processed foods with an average consumption of $3.6-4.5 \mathrm{~kg}$ of food additives per person per year, some of which may consume even more (Linke et al., 2018).

Food additives include colors, preservatives, antioxidants, acids, flavors, artificial sweeteners, and stabilizers (Baig and Kasim, 2018). Coloring agents are defined, according to the FDA, as any pigment or dye that can impart color when added to food, medications, or cosmetics to increase the visual appeal (Martins et al., 2016).

Tartrazine is frequently used as a yellow coloring agent in a wide range of food products such as ice cream, pastries, hard candy, cotton candy, soft drinks, alcoholic beverages, sports drinks, chewing gum, chocolate snacks, cereals, cake mixes, soups, sauces, jam and jelly (Bonciu et al., 2020).

It is added to non-food products such as cosmetics (lipstick, face powder, eye shadow and foundation), soaps and shampoo. It is also used in cooking as a replacement for saffron in developing countries (Mehedi et al., 2009).

Tartrazine has been linked to the development of several disorders including behavioral changes (Oyewole and Oladele, 2016), hypersensitivity reactions (Leo et al., 2018), gastrointestinal (El Rabey et al., 2019), renal (Ali et al., 2016), hormonal (Abdel-Aziz et al., 2019), endocrinal (El-sakhawy et al., 2019), hematological (Abd-Elhakim et al, 2018) and teratogenic (Hashem et al., 2019) potentials.

Decreased antioxidant defense mechanisms and free radical development cause oxidative stress that further damage the proteins, lipids, mitochondrial enzymes, and DNA and cause neuronal degradation (Yadav et al., 2019).

Artificial food colorants are considered safe if consumed within the acceptable daily intake (ADI) limit. However, increased consumption of these colorants may result in many hazards especially in children due to their low body weights. Children, especially in the developing countries, are the major consumers of colored food products so they are at high risk because they most often exceed prescribed ADIs (Reza et al., 2019).

So, the aim of the present study was to evaluate the toxic effects induced by oral administration of tartrazine on the brain of young male albino rats.

\section{MATERIAL AND METHODS 1-Material:}

(A) Chemicals:

- Tartrazine: Obtained from Alfa Aesar, Germany via The International Company for Scientific and Medical Supplies, Cairo in the form of orange powder with dye content $>85 \%$.

- Distilled water: Obtained from El- Nasr Co, Egypt and used as a solvent for tartrazine.

- Reagents and commercial kits: kits for estimation of GPx and MDA were purchased from Bio diagnostic Co., Egypt.

(B)Animals :

Eighteen young male albino rats (28 days old) (El-Helbawy et al., 2017) weighing about 60-80 gm each were included in this study. They were obtaine d from the Animal House of the Faculty of Medicine, Zagazig University. The animals were apparently healthy and were acclimatized to their new environment for 1 week prior to the experiment and received basic laboratory diet. The study was conducted in The Departments of Physiology \& Forensic 
medicine and Clinical Toxicology, Faculty of Medicine, Zagazig University. All animals received care in compliance with the Animal Care Guidelines and Ethical Regulations in accordance with "The Guide for the Care and Use of Laboratory Animals" (ILAR, 2011). Rats were randomly divided into 3 groups (6 rats per group):

Group I (Negative control): Each rat received only regular diet and tap water to measure the basic parameters.

Group II (Positive control): Each rat received $1 \mathrm{ml}$ distilled water as a solvent of tartrazine (Khayyat et al., 2017) once daily by oral gavage for 4 weeks.

Group III (Tartrazine group): Each rat received $320 \mathrm{mg} / \mathrm{kg} \mathrm{B.W}$ tartrazine dissolved in $1 \mathrm{ml}$ distilled water once daily by oral gavage for 4 weeks (which represents $1 / 20$ of $L_{50}$ of tartrazine in rats).

Oral $\mathrm{LD}_{50}$ of tartrazine for rats is 6375 $\mathrm{mg} / \mathrm{kg}$ body weight (Boussada et al., 2017).

At the end of the experiment $(24$ hours from the last dose of each substance) the rats of all groups were exposed to diethyl ether inhalation followed by decapitation (El-sakhawy et al., 2019). Skulls of sacrificed animals were dissected, and the brains were obtained and prepared for estimation of oxidative stress in the brain tissue by measuring glutathione peroxidase (GPx) activity and malondialdehyde (MDA) level. Sections of the brain were examined under light microscope for detection of histopathological changes.

\section{2-Methods:}

Samples were prepared according to Mohamed et al. (2015). Skulls of the sacrificed rats were opened; brains were immediately dissected out and grossly inspected to assess any gross abnormalities and

washed with cold normal saline to remove any excess blood.

To prepare tissue extracts, cerebral hemispheres of all groups were separated. The left cerebral hemispheres from all groups were cut into small pieces for homogenate preparation. The homogenate was prepared using an electrical homogenizer by mixing $0.5 \mathrm{~g}$ of tissue with $5 \mathrm{ml}$ phosphate buffered saline (PBS) at $4^{\circ} \mathrm{C}$. Then homogenates were centrifuged at $3000 \mathrm{rpm}$ for $15 \mathrm{~min}$. Then, the collected supernatant was conserved (at $-20^{\circ} \mathrm{C}$ ) until further use for the biochemical examination (oxidative stress biomarkers). The right cerebral hemispheres from all groups were fixed in $10 \%$ neutral buffered formalin for subsequent histopathological study.

B iochemical study:

Oxidative stress biomarkers:

To prepare tissue extract, part of the brain was preserved immediately in liquid nitrogen for homogenate preparation and estimation of brain tissue:

1- Glutathione peroxidase: Assessment of glutathione peroxidase (GPx) activity was based on the method of (Paglia and Valentine, 1967).

2- Malondialdehyde level: Malondialdehyde (MDA) concentration was measured according to the method of (Ohkawa et al., 1979).

Histopathological study: Light micros copic examination:

The other part of brain specimens was fixed in $10 \%$ neutral buffered formalin for 48 hours. The fixed specimens were washed in distilled water then dehydrated in ascending grades of ethyl a lcohol each for one hour then in absolute alcohol for one hour. Specimens were cleared in xylene for 2 hours, embedded in soft paraffin for 2 hours and in hard for 2 
hours. Sections of 3-4 $\mu \mathrm{m}$ in thickness were obtained by rotatory microtome and prepared for staining (Bancroft and Gamble, 2008). These sections were stained with Haematoxylin \& Eosin (H\&E) (Kiernan, 1999) then examined under light microscope.

\section{Statis tical analysis :}

Statistical Package for the Social Sciences (SPSS version 20.0) software was used for data analysis (Kirkpatrick and Feeney, 2012). Data were expressed as mean \pm standard deviation (mean \pm SD). Statistically significant difference between groups was detected by one-way analysis of variance ANOVA, followed by the least significant difference (LSD) test. Probability $(\mathrm{P}$ value $) \geq 0.05$ was considered non-significant, $\quad<0.05$ significant and $<0.001$ highly significant.

\section{III- RESULTS}

(I) Bioche mical results:

Oxidative stress biomarkers: Glutathione peroxidase (GPx) and Malondialdehyde (MDA) in brain tissue:

$\begin{array}{ccr}\text { There } & \text { was no } & \text { statistically } \\ \text { significant } & \text { difference } & (\mathrm{P} \geq 0.05)\end{array}$ between negative control and distilled water groups regarding brain tissue levels of GPx and MDA all over the period of the study. Regarding GPx levels among (-ve) control (group I), distilled water (group II) and tartrazine (group III), there was highly significant reduction in the mean value of GPX (ng/mg) activity in tartrazine group when compared with other groups of the study $(\mathrm{P}<0.001)$. As regard MDA levels among (-ve) control (group I), distilled water (group II) and tartrazine (group III), there was highly significant elevation in the mean value of MDA $(\mathrm{nmol} / \mathrm{mg})$ in tartrazine group when compared with other groups of the study $(\mathrm{P}<0.001)$ (Table 1).

(II) His topathological results: 1-Gross examination:

Zagazig J. Forensic Med.\& Toxicology [Type here]
Macroscopic examination of the brain of all the studied groups revealed normal appearance with no abnormal masses. Cut sections were normal.

\section{2-Light microscopic examination:}

Examination of $\mathrm{H} \& \mathrm{E}$ stained sections of the rat cerebrum of the negative control and distilled water groups showed nearly the same histological picture. Cerebral cortex of the control group was covered by pia matter layer. The gray matter showed six layers with scattered neuronal and glial supporting cells (Figure 1a). Its neuronal cells were of variable sizes and shapes. The most prominent cells were pyramidal cells. They had pale open face nuclei and long processes. Granular cells had large open face nuclei and prominent nucleoli. Astrocytes, oligode ndrocytes, and perineural glial cells were noticed in the gray matter. Neuropil appeared acidophilic and contained blood vessels with narrow peri-vascular spaces among the neurons (Figure 1b). The white matter contained aggregations of regularly packed nerve fibers and neuroglia cells that were noticed in rows in between the fibers (Figure 1c). Sections of the cerebral cortex of tartrazine group showed pia matter separation from the underlying gray matter, neuronal cells had dark stained nuclei and aggregated small dark nuclei. Neuropil showed areas of separation and blood vessels were dilated, congested, and had wide perivascular spaces (Figure 2a). Also, other sections revealed marked increase in the number of neuroglia cells. Vacuolated neuropil showed apoptotic cells, cells with shrunken irregular dark nuclei and cells with cytoplasmic remnants (Figure $2 b$ ). The white matter of the same group showed marked irregularly arranged nerve fibers and glia cells. Thickened fibers

\section{Zagarig J. Forensic Med.\& Toxicology [Type here]}

Vol. (19) No. (1) January 2021 
in the neuropil were also detected

(Figure

2c).

Table (1): Comparison between group I (negative control), group II (distilled water) and group III (tartrazine) regarding the mean values of GPx and MDA in the brain tissue of young male albino rats using ANOVA test.

\begin{tabular}{||l|c|c|c|c|c||}
\hline \multirow{2}{*}{ Group } & $\begin{array}{c}\text { Group I } \\
\text { (-ve) control }\end{array}$ & $\begin{array}{c}\text { Group II } \\
\text { distilled water }\end{array}$ & $\begin{array}{c}\text { Group III } \\
\text { Tartrazine }\end{array}$ & \multirow{2}{*}{ F } & \multirow{2}{*}{ P } \\
\cline { 2 - 4 } & Mean \pm SD & Mean \pm SD & Mean \pm SD & \\
\hline $\begin{array}{l}\text { GPx } \\
(\mathbf{n g} / \mathbf{m g}):\end{array}$ & $27.4 \pm 0.27$ & $27.86 \pm 0.13$ & $14.24 \pm 0.92 \mathrm{a}$ & 1128.795 & $<0.001^{* *}$ \\
\hline $\begin{array}{l}\text { MDA } \\
(\mathbf{n m o l} / \mathbf{m g}):\end{array}$ & $52.17 \pm 2.32$ & $52.1 \pm 1.7$ & $102.5 \pm 0.46 \mathrm{a}$ & 1731.12 & $<0.001^{* *}$ \\
\hline
\end{tabular}

Number of rats in each group=6; SD: Standard Deviation;**: highly signific ant $(\mathrm{P}<0.001)$; GPx: Glutathione peroxidase; MDA: Malondialdehyde; ANOVA: Analysis of variance; a: signific antly different from controls (LSD test; $\mathrm{p}<0.001$ ).

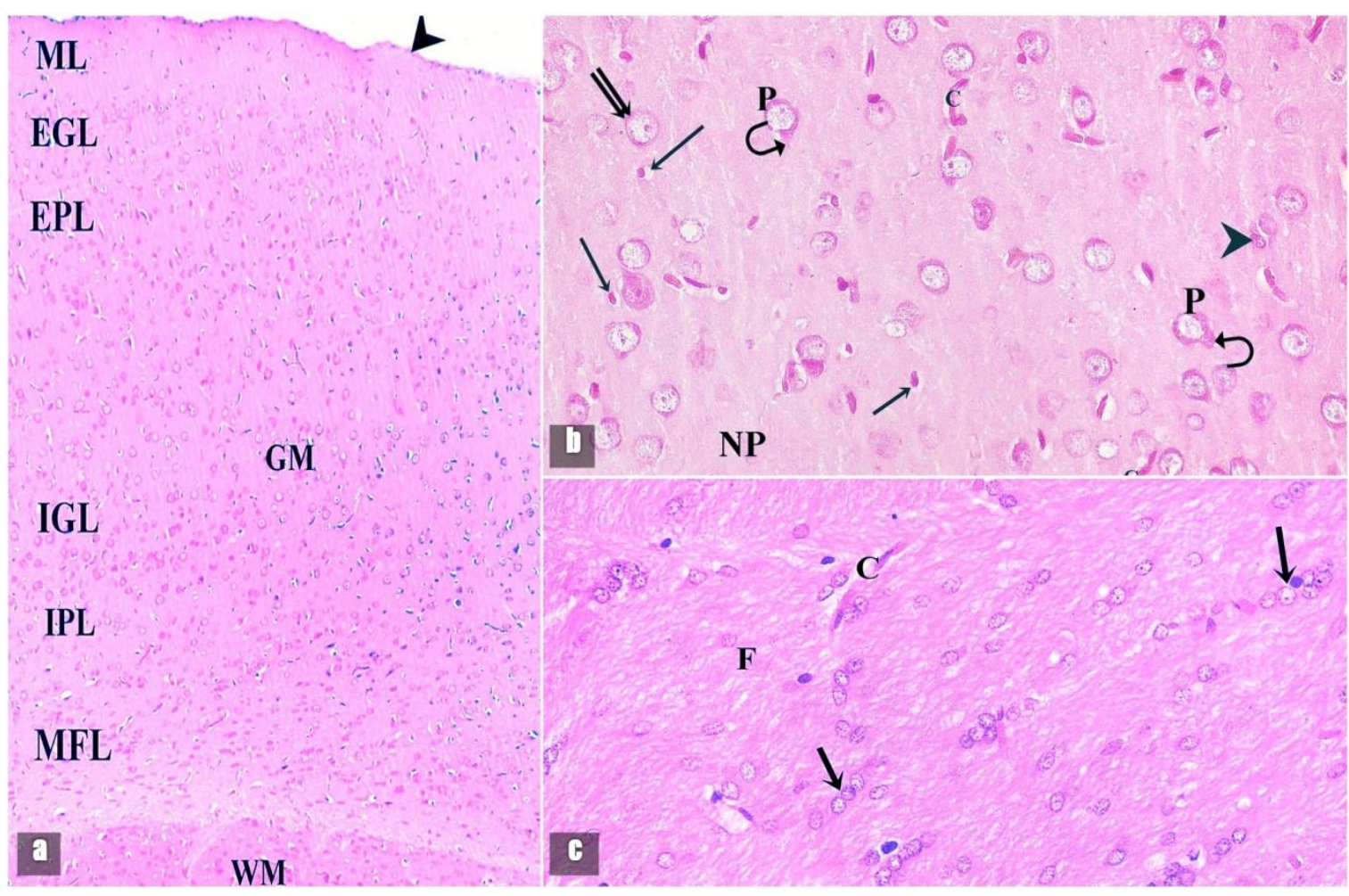

Figure (1): A photomicrograph of a section from the cerebral cortex of negative control group a: Showing the gray matter (GM) and white matter (WM). Pia matter (arrow head) covers the cortex. Gray matter is formed of six layers; I: Molecular Layer (ML), II: External Granular Layer (EGL), III: External Pyramidal Layer (EPL), IV: Internal Granular Layer (IGL), V: Internal Pyramidal Layer (IPL) and VI: Multiform Layer (MFL) (H\&Ex 100), b: Showing acidophilic neuropil (NP), pyramidal cells (P) with pale open face nuclei and neuronal processes (curved arrow), granular cells (double arrow) with large open face nuclei and prominent nucleoli, oligodendrocytes (arrow) have dark stained nuclei surrounded by perinuclear halo and astrocytes (arrow head) appear small with pale nuclei. Blood vessels (C)

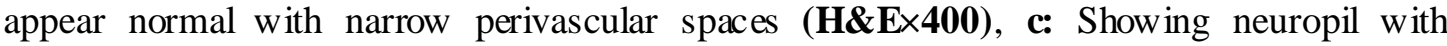
regularly packed nerve fibers $(\mathrm{F})$, rows of neuroglial cells (arrow) and normal capillaries $(\mathrm{C})$ (H\&E×400) (1a: scale bar $50 \mu \mathrm{m}, 1 \mathrm{~b}-1 \mathrm{c}$ : scale bar $20 \mu \mathrm{m})$. 

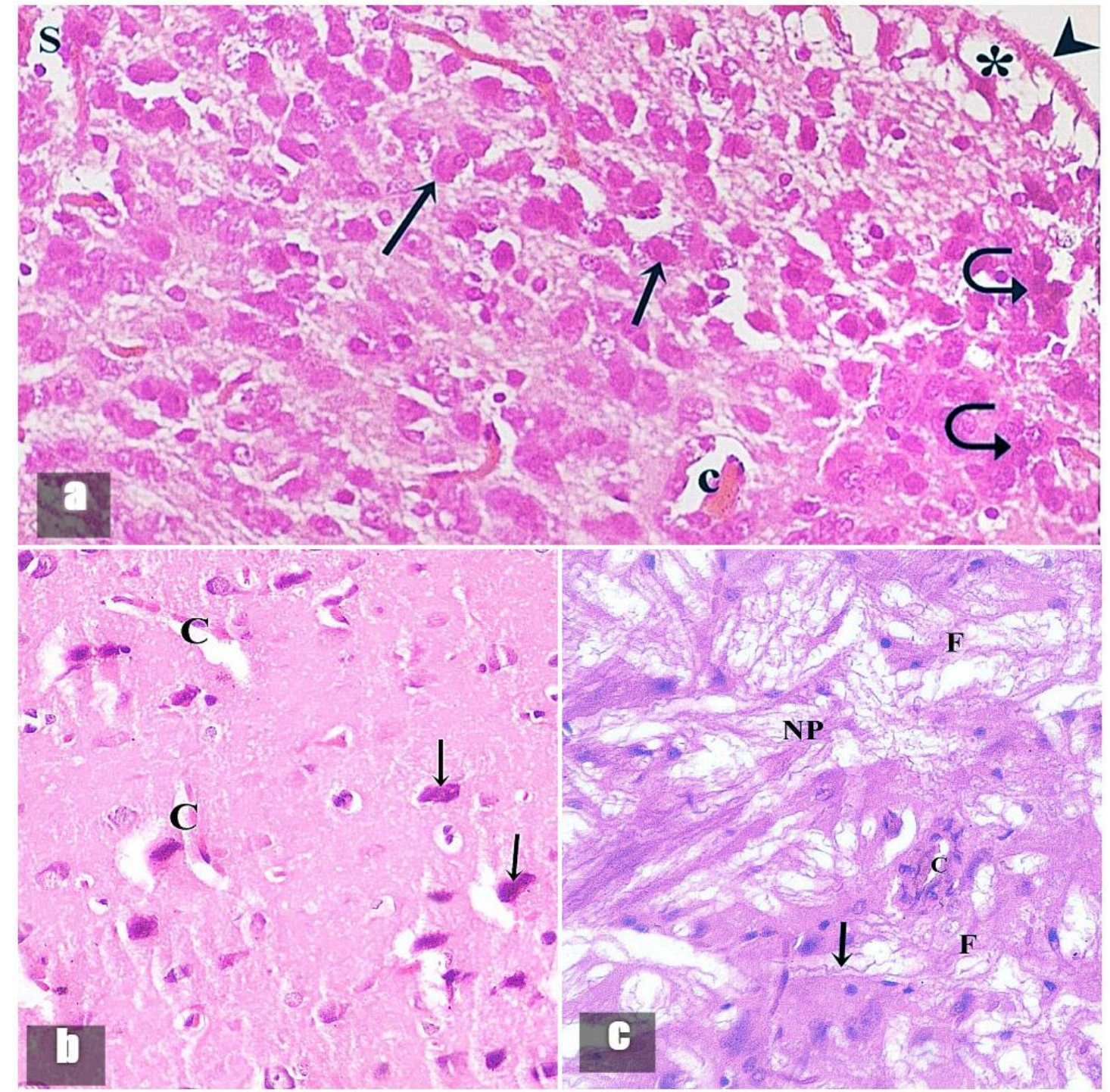

Figure (2): A photomicrograph of a section from the cerebral cortex of tartrazine-treated group a: Showing separation (*) of pia matter (arrow head) from the underlying cortex, neuropil with areas of separation (S) and dark stained nuclei of neuronal cells (arrow). Blood vessels (C) are dilated and congested with wide perivascular spaces. Aggregated small nuclei (curved arrow) are also detected, b: Showing shrunken irregular shaped nuclei (arrow) and capillaries (C) with wide perivascular spaces, c: Showing marked irregularly arranged nerve fibers (F) in the neuropil (NP), nuclei of glia cells (curved arrow), congested capillaries (C) and thickened fibers (arrow) in the white matter (H \& Ex400; scale bar $20 \mu \mathrm{m}$ ).

\section{VI- DISCUSSION}

Food dyes are added to foods and food products to make them look more appetizing and attractive (Mittal, 2020). Tartrazine, synthetic azo dye, provides yellow color to pharmaceutical, cosmetic and food products such as soft drinks, cereals, ice creams, chocolates, biscuits, and yoghurt (Rovina et al., 2017).

The harmful effect of tartrazine originates from reduction of the azo bond during metabolic process in the intestine producing free radicals (Elekima et al., 2019). Brain tissue contains large amounts of polyunsaturated fatty acids (PUFAs) 
which are strongly affected by oxidative stress (Chaudhary et al., 2014). When PUFAs get attacked by free radicals, lipid peroxides are generated (Samarghandian et al., 2017).

Lipid peroxidation can alter cell membrane integrity. After a while, persistent oxidative stress will result in irreversible loss of the brain and spinal cord cells besides damage of the nerve endings leading to disturbances in neurotransmitter transport and subsequent alteration in CNS functions (Hegazi et al., 2017).

The results of the present study revealed no statistically significant difference between rats of the control groups (negative \& positive control groups) as regard biochemical analys is (GPx and MDA). There were also no abnormal histopathological changes in the brains of the rats of these groups.

The present study showed that in tartrazine-treated group there was highly significant reduction in the mean value of GPx activity and highly significant elevation in the mean value of MDA level when compared with control groups.

Gao et al. (2011) reported dose dependent significant decline in GPx activity and significant increase of MDA level in the brain tissue as compared to the control rats after oral administration of different doses (250 and $500 \mathrm{mg} / \mathrm{kg}$ ) of tartrazine over thirty days.

It was found that $500 \mathrm{mg} / \mathrm{kg}$ of oral tartrazine given to rat pups on a daily basis for 30 days led to significant increase of MDA level in the cerebral cortex as compared to control group (Mohamed et al., 2015).

Bhatt et al. (2018) added that oral intake of tartrazine at the ADI (7.5 $\mathrm{mg} / \mathrm{kg} /$ day) for 40 consecutive days can produce oxidative damage in the brain of young rats as evidenced by significantly increased MDA levels in all studied brain sub-regions. They reported increase in the activity of GPX in all studied sub-regions that was explained as a compensatory mechanism for the associated depressed activity of other antioxidant enzymes; catalase, glutathione-stransferase, and glutathione reductase.

According to Eman et al. (2018), adult male albino rats which received oral tartrazine at a daily dose of 50 $\mathrm{mg} / \mathrm{kg}$ for 30 days showed significant decrease of GPX and significant (5 fold) increase of MDA levels in the cerebellar tissue.

Albasher et al. (2020) revealed that perinatal exposure to oral tartrazine within the ADI (2.5 and 5 $\mathrm{mg} / \mathrm{kg}$ daily) provoked significant increase of MDA in different brain regions (cerebrum, cerebellum, and medulla) in mice offspring.

The brain with its extensive capacity to consume large amounts of oxygen and production of free radicals is considered especially sensitive to oxidative damage (Salim, 2014). Glutathione peroxidase $(\mathrm{GPx})$ is an important intracellular enzyme that belongs to the first line of antioxidant defense system. It catalyzes breakdown of hydrogen peroxides $\left(\mathrm{H}_{2} \mathrm{O}_{2}\right)$ and lipid peroxides (Ighodaro and Akinloye, 2018). Glutathione peroxidase is present in many tissues, as well as in the neurons and glia of the CNS. In the rat and human CNS, the greatest activity of GPx is observed in the gray and white matters of the cerebral cortex (Hernández et al., 2016). According to Chabory et al. (2009), low GPx activity predisposes to impaired antioxidant protection, which in turn leads to oxidative damage to functional proteins and cell membrane fatty acids and eventually, neurotoxic damage. Malondialdehyde (MDA) is the main end product of lipid peroxidation that results from reaction of ROS with polyunsaturated fatty 
acids. It is the most frequently used biomarker for assessment of oxidative stress (Tsikas, 2017). According to Bawazir (2016), metabolism of tartrazine results in generation of free radicals which in turn inhibit the endogenous antioxidant defense system. Albasher et al. (2019) referred the decreased activity of GPx to increased production of superoxide anion which is converted to water by GPx. Antioxidant enzymes work in collaboration with each other. Defect in any of the enzyme activity may result in initiation of overall detrimental mechanism. Disturbance in activities of antioxidant enzymes may result in initiation of peroxidation processes of phospholipids in brain cells leading to brain damage and neurodegeneration (Liaquat et al., 2019).

In the present work, microscopic examination of the brain specimens of rats treated with tartrazine showed obvious changes in the general architecture of the brain. The frontal cortex showed an apparent separation of pia matter from the underlying grey matter with areas of separation and marked vacuolations in the neuropil. There was also marked apoptosis of neuronal and neuroglia cells and marked increase in the number of neuroglia cells. Blood vessels were dilated, congested with wide perivascular spaces. Meanwhile, the white matter of the same group showed marked irregularly arranged nerve fibers and glia cells, vacuolations and thickened fibers in the neuropil, marked cellular infiltration, dark stained nuclei (pyknosis) of glia cells and dilated congested capillaries.

As reported by Gao et al. (2011), tartrazine administered at an oral dose of $500 \mathrm{mg} / \mathrm{kg} /$ day for thirty days caused edema and vacuolations as well as features of apoptosis in the brain of studied rats.
It was found that oral tartrazine at a dose of $500 \mathrm{mg} / \mathrm{kg}$ daily given to rats for 30 days resulted in extensive myelin vacuolation in the white matter with few vacuolations of both the cerebrum and the cerebellum (Ghonimi and Elbaz, 2015).

Eman et al. (2018) added that tartrazine given to adult albino rats over a period of 30 days induced necrosis of purkinje cells in the cerebellum.

Hemorrhage and increased perivascular space in brains of rats treated with tartrazine was recorded by (Alsalman et al., 2019).

El-sakhawy et al. (2019) observed that oral tartrazine at the ADI caused cerebellar pathological changes in adult rats in the form of subcortical edema and blood vessels congestion, cytoplasmic vacuolations of the gray matter neurons, pyknosis and increase in the astrocytes population. The intensity of damage increases with increasing dose of tartrazine.

Subcortical edema and congestion in brains of mice were reported after 13-week administration of different doses of tartrazine (Mehedi et al., 2013).

Albasher et al. (2020) recorded development of cerebral neuronal degeneration, chromatolysis and pyknos is in mice offspring exposed to oral doses of tartrazine within the ADI range during the perinatal period.

The brain has an extremely poor antioxidant capacity (Motaghinejad et al., 2017). According to Bhatt et al. (2018), the frontal cerebral cortex is affected by oxidative damage more than other regions of the brain due to variability in the distribution of the antioxidant enzymes among different brain regions. Vacuolations detected in the brain can be the result of proteasome dysfunction and altered lipid metabolism (Mimnaugh et al., 2006 \& Franco and Cidlowski, 2009). 
Polyunsaturated fatty acids, which present in large amount in the brain, are vulnerable to free radical damage resulting in vacuolations in the cerebral cortex (Chaudhary et al., 2014). Oxidative stress can predispose to cell death through different signaling pathways. The production of free radicals may cause DNA damage and cellular apoptosis (Jayaraj et al., 2013). The histopathological changes observed in the present study were confirmed by the disturbed levels of oxidative stress biomarkers; MDA and GPx activity.

\section{V- CONCLUSION}

It can be concluded that tartrazine has neurotoxic effect that was clarified by increased oxidative stress in the brain tissue and confirmed by histopathological changes.

\section{IV- RECOMMENDATIONS}

- The use of tartrazine to color food and the consumption of such foods should be restricted as far as possible, especially for children.

CONFLICTS OF INTEREST: None

FUNDING: This research did not receive any specific grant from funding agencies in the public, commercial, or not-for-profit sectors.

\section{IIV-REFERENCES}

Abdel-Aziz, H. M.; Alazouny, Z. M.; Abdelfadeel, K. F. and Abohashem, A. A. (2019): Effect of tartrazine on thyroid gland of male rat and ameliorating role of curcumin (histological and immunohistochemical study). Journal of Biochemistry and Cell Biology, 2(1):2-11.

Abd-Elhakim, Y. M.; Hashem, M. M.; El-Metwally, A. E.; Anwar, A.; AboEL-Sooud, K.; Moustafa, G. G. and Ali, H. A. (2018): Comparative haemato-immunotoxic impacts of long-term exposure to tartrazine and chlorophyll in rats. International Immunopharmacology, 63(1):145-154.

Zagazig J. Forensic Med.\& Toxicology [Type here]
Albasher, G.; Abdel-Daim, M. M.; Almeer, R.; Ibrahim, K. A.; Hamza, R. Z.; Bungau, S. and Aleya, L. (2019): Synergistic antioxidant effects of resveratrol and curcumin against fipronil-triggered oxidative damage in male albino rats. Environmental Science and Pollution Research, 26(36):1-10.

Albasher, G.; Maashi, N.; Alfarraj, S.; Almeer, R.; Albrahim, T.; Alotibi, F. and Mahmoud, A. M. (2020): Perinatal exposure to tartrazine triggers oxidative stress and neurobehavioral alterations in mice offspring. Antioxidants, 9(1): 53-67.

Ali, F. A.; Abdelgayed, S. S.; ElTawil, O. S. and Bakeer, A. M. (2016): Toxicological and histopathological studies on the effect of tartrazine in male albino rats. International Journal of Biological, Biomolecular, Agricultural, Food \& Biotechnological Engineering, 10(8): 513-518.

Alsalman, N.; Aljafari, A.; Wani, T. A. and Zargar, S. (2019): High-dose aspirin reverses tartrazine-induced cell growth dysregulation independent of p53 signaling and antioxidant mechanisms in rat brain. Biomed Research International, 2019(1):1-8.

Baig, S. K. M. S. and Kasim, S. S. (2018): Study of harmful effects of consuming food additives and public awareness. International Journal of Scientific Research in Science and Technology, 4(2):1071-1074.

Bancroft, J. D. and Gamble, M. (2008): Theory and Practice of Histological Techniques, $6^{\text {th }}$ edition. Churchill Livingstone, London, Edinburgh, New York, Philadelphia, PP. 245. 
Bawazir, A. E. (2016): Effects of food colourallura red (No. 129) on some neurotrans mitter, antioxidant functions and bioele ment contents of kidney and brain tissues in male albino rats. Life Science Journal, 13(12):10-17.

Bhatt, D.; Vyas, K.; Singh, S.; John, P. J. and Soni, I. (2018): Tartrazine induced neurobiochemical alterations in rat brain sub-regions. Food and Chemical Toxicology, 113(3):322-327.

Bonciu, E.; Rosculete, E. and Rosculete, C. (2020): The clastogenic effect of tartrazine, a synthetic yellow dye, in plant meristematic tissues. Annals of the University of Craiova-Agriculture, Montanology, Cadastre Series, 49(1):32-35.

Boussada, M.; Lamine, J. A.; Bini, I.; Abidi, N.; Lasrem, M.; El-Fazaa, S. and El-Golli, N. (2017): Assessment of a sub-chronic consumption of tartrazine (E102) on sperm and oxidative stress features in Wistar rat. International Food Research Journal, 24(4):1473-1481.

Chabory, E.; Damon, C.; Lenoir, A.; Kauselmann, G.; Kern, H.; Zevnik, B. and Schoor, M. (2009): Epididymis seleno-independent glutathione peroxidase 5 maintains sperm DNA integrity in mice. The Journal of Clinical Investigation, 119(7):20742085.

Chaudhary, M.; Joshi, D. K.; Tripathi, S.; Kulshrestha, S. and Mahdi, A. A. (2014): Docosahexaenoic acid ameliorates aluminum induced biochemical and morphological alteration in rat cerebellum. Annals of Neurosciences, 21(1):5-9.

El Rabey, H. A.; Al-Seeni, M. N.; Al-Sieni, A. I.; Al-Hamed, A. M.; Zamzami, M. A. and Almutairi, F. M. (2019): Honey attenuates the toxic Zagazig J. Forensic Med.\& Toxicology [Type here] effects of the low dose of tartrazine in male rats. Journal of Food Biochemistry, 43(4):1-11.

Elekima, I.; Nwachuku, O. E.; Ukwukwu, D.; Nwanjo, H. U. and Nduka, N. (2019): Biochemical and histological changes associated with azo food dye (Tartrazine) in male albino rats. Asian Journal of Research in Biochemistry, 5(1):1-14.

El-Helbawy, N. F.; Radwan, D. A.; Salem, M. F. and El-Sawaf, M. E. (2017): Effect of monosodium glutamate on body weight and the histological structure of the zonafasciculata of the adrenal corte $x$ in young male albino rats. Tanta Medical Journal, 45(2):104-113.

El-sakhawy, M. A.; Mohamed, D. W. and Ahmed, Y. H. (2019): Histological and immunohistochemical evaluation of the effect of tartrazine on the cerebellum, submandibular glands, and kidneys of adult male albino rats. Environmental Science and Pollution Research, 26(10):9574-9584.

Eman, G. M.; Ibrahim, M. A. L.; Hassan, A. H. and Ebtehal, M. F. (2018): Quercetin nanoparticles repressed liver and brain toxicities induced by tartrazine in rats. Journal of Drug Delivery and Therapeutics, 8(5):230-240.

Franco, R. and Cidlowski, J. A. (2009): Apoptosis and glutathione: Beyond an antioxidant. Cell Death and Differentiation, 16(10):1303-1314.

Gao, Y.; Li, C.; Shen, J.; Yin, H.; An, X. and Jin, H. (2011): Effect of food azo dye tartrazine on learning and memory functions in mice and rats, and the possible mechanisms involved. Journal of Food Science, 76(6):125-129. 
Ghonimi, W. A. and Elbaz, A. (2015): Histological changes of selected wistar rat tissues following the ingestion of tartrazine with special emphas is on the protective effect of royal jelly and cod liver oil. Journal of Cytology \& Histology, 6(4):1-6.

Hashem, M. M.; Abd-Elhakim, Y. M.; Abo-EL-Sooud, K. and Eleiwa, M. M. (2019): Embryotoxic and teratogenic effects of tartrazine in rats. Toxic ological Research, 35(1):7581.

Hegazi, M. A. M.; Basyuni, M. A.; Salim, E. S. I. and Alaasar, S. R. (2017): Oxidative stress in liver and brain of male growing rats supplemented benzene sulfonic acid. The Egyptian Journal of Experimental Biology (Zoology), 13(2):305-314.

Hernández, J. A.; López-Sánchez, R. C. and Rendón-Ramírez, A. (2016): Lipids and oxidative stress associated with ethanol-induced neurological damage. Oxidative Medicine and Cellular Longevity, 2016(1):1-15.

Ighodaro, O. M. and Akinloye, O. A. (2018): First line defense antioxidantssuperoxide dismutase (SOD), catalase (CAT) and glutathione peroxidase (GPX): Their fundamental role in the entire antioxidant defense grid. Alexandria Journal of Medicine, 54(4):287-293.

ILAR (Institute of Laboratory Animal Resources) (2011): Guide for the Care and Use of Laboratory Animals.

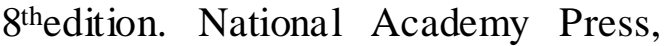
Washington DC, PP. 21-55.

Jayaraj, R. L.; Tamilselvam, K.; Manivasagam, T. and Elangovan, N. (2013): Neuroprotective effect of CNB-001, a novel pyrazole derivative of curcumin on biochemical and apoptotic markers against rotenone- induced SK-N-SH cellular model of Parkinson's disease. Journal of Molecular Neuroscience, 51(3):863870.

Khayyat, L.; Essawy, A.; Sorour, J. and Soffar, A. (2017): Tartrazine induces structural and functional aberrations and genotoxic effects in vivo. The Journal of Life and Environmental Sciences, 5(1):30413055 .

Kiernan, J. A. (1999): Histological and histochemical methods: Theory and practice. Shock, 12(6):479-480.

Kirkpatrick, L. and Feeney, B. (2012): One-way between-groups ANOVA. In: A simple guide to IBM SPSS statistics for version 20.0., Kirkpatrick, L., and Feeney, B. (eds.), Chapter $10,12^{\text {th }}$ edition. Wadsworth Cengage Learning, Belmont, USA, PP. 38-48.

Leo, L.; Loong, C.; Ho, X. L.; Raman, M. F. B.; Suan, M. Y. T. and Loke, W. M. (2018): Occurrence of azo food dyes and their effects on cellular inflammatory responses. Nutrition, 46(2):36-40.

Liaquat, L.; Sadir, S.; Batool, Z.; Tabassum, S.; Shahzad, S.; Afzal, A. and Haider, S. (2019): Acute aluminum chloride toxicity revisited: Study on DNA damage and histopathological, biochemical and neurochemical alterations in rat brain. Life Sciences, 217(2):202-211.

Linke, B. G.; Casagrande, T. A. and Cardoso, L. I. A. (2018): Food additives and their health effects: A review on preservative sodium benzoate. African Journal of Biotechnology, 17(10):306-310. 
Martins, N.; Roriz, C. L.; Morales, P.; Barros, L. and Ferreira, I. C. (2016): Food colorants: Challenges, opportunities, and current desires of agro-industries to ensure consumer expectations and regulatory practices. Trends in Food Science \& Technology, 52(6):1-15.

Mehedi, N.; Ainad-Tabet, S.; Mokrane, N.; Addou, S.; Za oui, C.; Kheroua, O. and Saidi, D. (2009): Reproductive toxicology of tartrazine (FD and C Yellow No. 5) in Swiss albino mice. American Journal of Pharmacology and Toxicology, 4(4):130-135.

Mehedi, N.; Mokrane, N.; Alami, O.; Ainad-Tabet, S.; Zaoui, C.; Kheroua, O. and Saidi, D. (2013): A thirteenweek ad libitum administration toxicity study of tartrazine in Swiss mice. African Journal of Biotechnology, 12(28):4519-4529.

Mimnaugh, E. G.; Xu, W.; Vos, M.; Yuan, X. and Neckers, L. (2006): Endoplasmic reticulum vacuolization and valosin-containing protein relocalization result from simultaneous hsp90 inhibition by geldanamycin and proteasome inhibition by velcade. Molecular Cancer Research, 4(9):667-681.

Mittal, J. (2020): Permissible Synthetic Food Dyes in India. Resonance, 25(4):567-577.

Mohamed, A. A. R.; Galal, A. A. and Elewa, Y. H. (2015): Comparative protective effects of royal jelly and cod liver oil against neurotoxic impact of tartrazine on male rat pups' brain. Acta Histochemica, 117(7):649-658.

Motaghinejad, M.; Motevalian, M.; Fatima, S.; Faraji, F. and Mozaffari, S. (2017): The neuroprotective effect of curcumin against nicotine-induced neurotoxicity is mediated by CREBBDNF

pathway. Neurochemical

research, 42(10):2921-2932.

Ohkawa, H.; Ohishi, N. and Yagi, K. (1979): Assay for lipid peroxides in animal tissues by thiobarbituric acid reaction. Analytical

Biochemistry, 95(2):351-358.

Oyewole, O. I. and Oladele, J. O. (2016): Assessment of cardiac and renal functions in $\mathrm{W}$ istar albino rats administered carmoisine and tartrazine. Advances in Biochemistry, 4(3):21-25.

Paglia, D. E. and Valentine, W. N. (1967): Studies on the quantitative and qualitative characterization of erythrocyte glutathione peroxidase. The Journal of Laboratory and Clinical Medicine, 70(1):158-169.

Pavithra, K. G. and Jaikumar, V. (2019): Removal of colorants from wastewater: A review on sources and treatment strategies. Journal of Industrial and Engineering Chemistry, 75(7): 1-19.

Reza, M. S. A.; Hasan, M. M.; Kamruzzaman, M.; Hossain, M. I.; Zubair, M. A.; Bari, L. and Islam, K. (2019): Study of a common azo food dye in mice model: Toxicity reports and its relation to carcinogenicity. Food Science \& Nutrition, 7(2):667-677.

Rovina, K.; Siddiquee, S. and Shaarani, S. M. (2017): A review of extraction and analytical methods for the determination of tartrazine (E 102) in foodstuffs. Critical Reviews in Analytical Chemistry, 47(4):309-324.

Salim, S. (2014): Oxidative stress and psychological disorders. Current Neuro pharmacology, 12(2):140-147. 
Samarghandian, S.; Azimi-Nezhad, M.; Farkhondeh, T. and Samini, F. (2017): Anti-oxidative effects of curcumin on immobilization-induced oxidative stress in rat brain, liver and kidney. Biomedicine \& Pharmacotherapy, 87(3):223-229.

Tsikas, D. (2017): Assessment of lipid peroxidation by measuring malondialdehyde (MDA) and relatives in biological samples: Analytical and biological challenges. Analytical Biochemistry, 524(9):13-30.
Yadav, M.; Jindal, D. K.; Parle, M.; Kumar, A. and Dhingra, S. (2019): Targeting oxidative stress, acetylcholinesterase, proinflammatory cytokine, dopamine and GABA by eucalyptus oil (Eucalyptus globulus) to alleviate ketamine-induced psychosis in

rats. Inflammopharmacology, 27(2):30 $1-311$. 
الآثار السامة لملون الطعام التارترازين على المخ في ذكور الجرذان البيضاء الصغيرة: دور

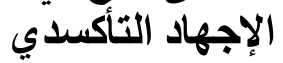

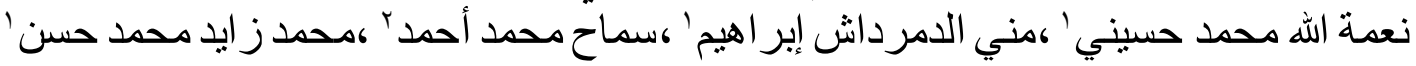

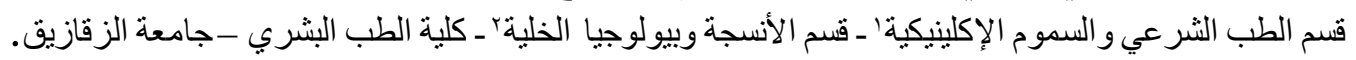

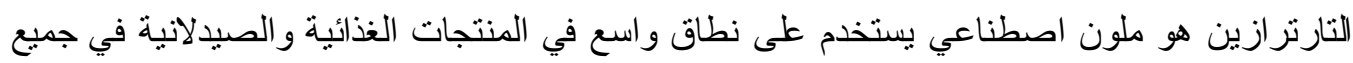

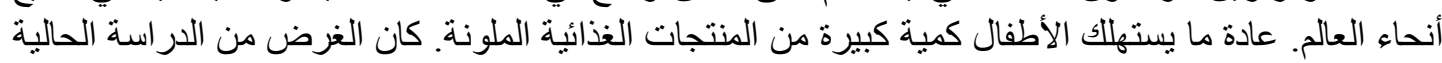

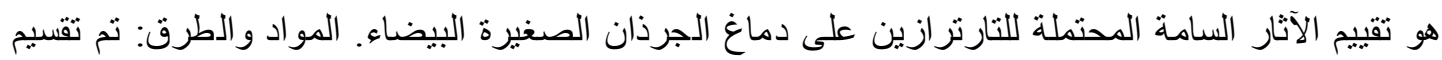

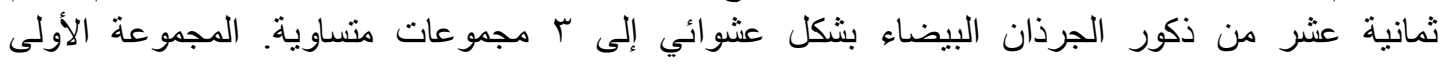

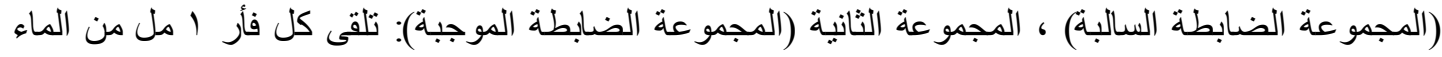

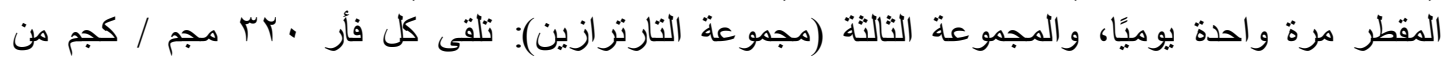

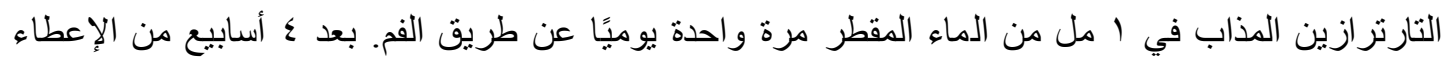

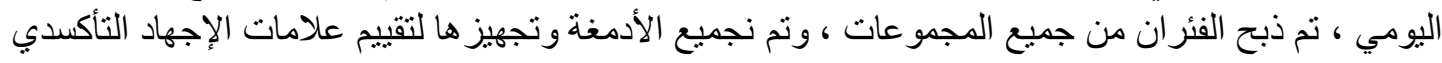

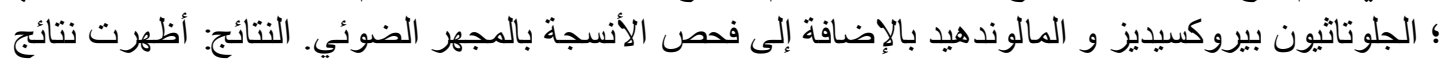

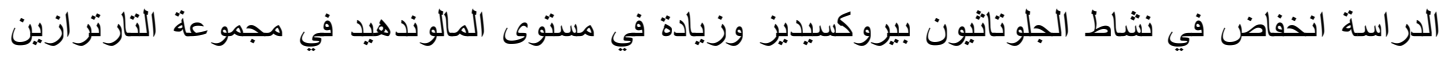

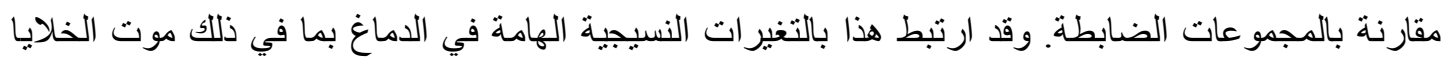

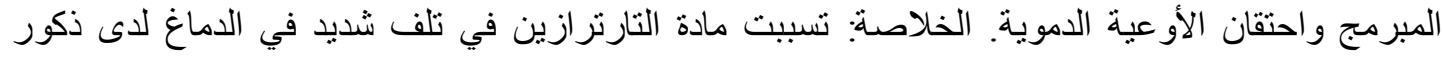

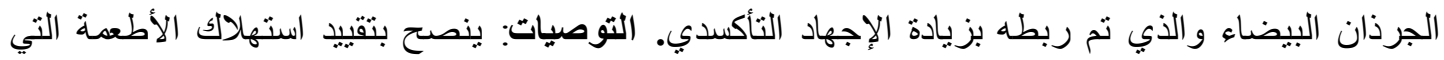
تحتوي على ملونات التارتز ازين وخاصة لـن للأطفال. 